\title{
AS COMPETÊNCIAS DOS ADMINISTRADORES: SEU PROCESSO DE FORMAÇÃO E AS EXIGÊNCIAS DO MERCADO DE TRABALHO
}

\author{
BUSINESS MANAGERS COMPETENCES: ITS DEVELOPMENT PROCESS AND \\ LABOR MARKET DEMANDS
}

\section{LAS HABILIDADES DE LOS ADMINISTRADORES: SU PROCESSO DE FORMACIÓN Y LAS NECESIDADES DEL MERCADO DE TRABAJO}

Priscilla de Oliveira Martins-Silva

Doutora em Psicologia pela Universidade

Federal do Espírito Santo (UFES), Brasil;

Professora da UFES

fdmotke@gmail.com

\section{Camila Santos Silva}

Especialista em Gestão Estratégica de Pessoas

pela Fundação Instituto Capixaba de Pesquisas

em Contabilidade, Economia e Finanças

(FUCAPE), Brasil; Analista de Recursos Humanos

camilasotnass@gmail.com

\section{Annor da Silva Junior}

Doutor em Administração pela Universidade

Federal de Minas Gerais (UFMG), Brasil;

Professor da UFES

annorsj@gmail.com
Contextus

ISSNe 2178-9258

Organização: Comitê Científico Interinstitucional Editor Científico: Carlos Adriano Santos Gomes

Avaliação : Double Blind Review pelo SEER/OJS

Revisão: Gramatical, normativa e de formatação

Recebido em 26/02/2016

Aceito em 09/06/2016

$2^{a}$ versão aceita em 22/08/2016

\section{RESUMO}

Investigou-se o ponto de vista dos administradores inscritos no Conselho Regional de Administração do Espírito Santo (CRA/ES) sobre as competências individuais voltadas para o trabalho e para o exercício profissional. Utilizaram-se as quinze competências profissionais identificadas por Sant'Anna; Moraes e Kilimnik (2005) como referência. Sobre a competência investigou-se duas perspectivas complementares: o processo de formação de competências e as competências requeridas pelo mercado de trabalho. Realizou-se uma pesquisa do tipo survey interseccional, com dados coletados por meio de questionário. Os resultados indicam que na visão dos respondentes todas as quinze competências individuais investigadas são demandadas em grande escala pelo mercado de trabalho. Em relação ao processo de formação das competências, verifica-se que tanto a formação educacional de nível superior (educação formal) quanto à experiência de vida (educação informal e não formal) contribuem para o desenvolvimento das competências, porém, a experiência de vida contribui de forma mais significativa.

Palavras-chave: Competências. Formação educacional. Experiência de vida. Experiência profissional. Mercado de trabalho. 


\begin{abstract}
It was investigated the point of view of business managers registered at the Regional Administration Board at Espírito Santo state (RAB/ES) about individual competences for work and professional practice. It was used the fifteen competences identified by Sant'Anna; Moraes and Kilimnik (2005) as a reference. It was investigated two complementary perspectives on competences: the development process of competences and labor market required competences. The research was characterized as an intersectional survey and data were collected through questionnaire. The results indicate that the fifteen individual competences are demanded in great scale by labor market according to all respondents surveyed. Regarding the development process of competences, it turns out that much of the educational level (formal education) and life experience (non-formal and informal education) contribute to competences' development, but life experience contributes more significantly.
\end{abstract}

Keywords: Competences. Educational development. Life experience. Professional experience. Labor market.

\title{
RESUMEN
}

Hemos investigado el punto de vista de los administradores registrados en el Consejo Regional del estado de Espírito Santo (CRA/ES) sobre las competencias individuales para el trabajo y la práctica profesional. Se utilizaron las quince competencias profesionales identificadas por Santa Ana; Kilimnik y Moraes (2005). Sobre competencia se investigaron dos perspectivas complementarias: la formación de competencias y las competencias requeridas por el mercado de trabajo. Se realizó una encuesta interseccional y los datos fueron recolectados vía cuestionarios. Los resultados indican que para los entrevistados las quince competencias individuales son requeridas a gran escala por el mercado de trabajo. En relación al proceso de formación de competencias, se encontró que tanto la formación educativa en el nivel superior (educación formal) y la experiencia de la vida (educación informal y no formal) contribuyen al desarrollo de competencias, sin embargo, la experiencia de vida contribuye más significativamente.

Palabras clave: Competencias. Formación educativa. Experiencia de vida. Experiencia professional. Mercado de trabajo.

\section{INTRODUÇÃ̃o}

Discute-se neste artigo a noção de competências individuais voltadas para o trabalho e para o exercício profissional (LE BOTERF, 2003; ZARIFIAN, 2003; FLEURY; FLEURY, 2001; SANT'ANNA; MORAES; KILIMNIK, 2005). Para isso, conduziu-se uma pesquisa survey interseccional (BABBIE, 2005) junto a administradores inscritos no Conselho
Regional de Administração do Espírito Santo (CRA-ES).

Teoricamente o estudo articula fundamentalmente aspectos relacionados à formação educacional e profissional do administrador e o conceito de competência. Para a discussão acerca da formação educacional e profissional do administrador, articulam-se três modalidades de educação apontadas por Gohn (2006), a educação informal, a educação não formal e a 
educação formal, por entender que somente pela articulação entre essas três modalidades de educação é que é possível discutir as questões relativas à formação educacional e profissional do administrador.

Fleury e Fleury (2001) apontam que as discussões sobre competências podem ser empreendidas em três níveis distintos de compreensão do conceito: (a) no nível da pessoa ou a competência do indivíduo; (b) no nível das organizações ou as core competences; e (c) no nível dos países que envolvem os sistemas educacionais $\mathrm{e}$ formação de competências. No nível da competência do indivíduo, as discussões podem ser articuladas do ponto de vista individual e profissional (LE BOTERF, 2003; ZARIFIAN, 2003; FLEURY; FLEURY, 2001) e do ponto de vista coletivo, em que as competências são vistas de forma mais ampliada, cujo corpo coletivo das equipes e da cultura organizacional ultrapassa a simples soma das competências individuais, por se reestruturar por meio da potencialização sinérgica das mesmas (ZAGO; SOUZA; BEZERRA, 2007). No nível organizacional introduz-se a noção de organização como uma carteira de competências em que é possível estabelecer uma relação entre as competências e a estratégia organizacional (FLEURY;
FLEURY, 2001). No nível dos países adotase uma abordagem mais ampla em que a análise do contexto social, político e econômico é relevante para compreender o sistema educacional de um país em termos das suas potencialidades no processo de formação de competências (FLEURY; FLEURY, 2001).

Nesta pesquisa, adotou-se a noção de competência desenvolvida por Le Boterf (2003) que articula três eixos formados, (a) pela pessoa em termos de sua biografia e socialização, (b) pela sua formação educacional e (c) pela sua experiência profissional. Em outros termos, a competência representa um conjunto de aprendizagens sociais e comunicacionais nutridas na origem pela aprendizagem e pela formação que, ao ser colocado em ação, produzirá resultados que serão submetidos a um sistema de avaliação qualquer.

A perspectiva de Le Boterf (2003) demonstrou ser adequada e coerente com a proposta de pesquisa empreendida neste estudo, que teve como escopo investigar o ponto de vista de administradores sobre competências individuais voltadas para $\mathrm{O}$ trabalho e para o exercício profissional, mais especificamente, sobre o processo de formação de competências e as competências requeridas pelo mercado de 
trabalho. Essa adequação e coerência encontram fundamento no fato de que o conceito de competência de Le Boterf (2003) permite articular, simultaneamente, as três modalidades de educação apontadas por Gohn (2006) e os três níveis de compreensão da competência apontados por Fleury e Fleury (2001).

Colocado de outra forma, os três eixos formadores de competência individual proposto por Le Boterf (2003), desenvolvidos ao longo da vida da pessoa (neste caso específico, do profissional de administração), sofrem influencias direta das modalidades de educação informal, não formal e formal (GOHN, 2006). Essas competências individuais voltadas para o trabalho e para o exercício profissional são utilizadas pelo indivíduo na execução de atividades individuais e coletivas, com impacto nas dimensões pessoais e organizacionais. Além disso, considerando o fato de que o processo de desenvolvimento de competências é um processo formativo e que a formação ocorre em um contexto mais amplo que inclui os aspectos sociais, políticos e econômicos que constituem o sistema educacional de um país, é possível alcançar os três níveis apontados por Fleury e Fleury (2001).
A opção por investigar os administradores inscritos em órgão de classe (no caso o CRA/ES) fundamenta-se no fato de que esses profissionais são os únicos que tiveram uma formação educacional formal (GOHN, 2006) especializada para a área de gestão, em que o conceito de competência e a questão da formação de competências para a gestão organizacional são temas presentes nas estruturas curriculares (BRASIL, 2005). Assim, esses administradores além da formação obtida na educação informal e na educação não formal (GOHN, 2006) tiveram no curso superior de graduação em administração de empresas, a formação educacional especializada, cuja questão da competência é uma das exigências das Diretrizes Curriculares Nacionais (DCN) para o referido curso (BRASIL, 2005). Com isso, assume-se que esses profissionais sejam os mais indicados para apresentarem o seu ponto de vista sobre a competência em termos, da formação das mesmas e das exigências feitas pelo mercado de trabalho. Dentre a população de administradores, em razão do critério de acessibilidade, decidiuse por investigar os administradores inscritos no CRA/ES.

No contexto brasileiro, diversos estudos vêm sendo publicados sobre o tema competência (FLEURY; FLEURY, 2001; 
KILIMNIK; SANT'ANNA; LUZ; 2004; SANT'ANNA; MORAES; KILIMNIK, 2005; SANT'ANNA, 2008). Visando sistematizar e analisar a produção científica acerca do tema, Ruas et al. (2005) e Ruas et al. (2010) desenvolveram duas revisões de trabalhos acadêmicos publicados no Brasil entre 2000 e 2004 e entre 2000 e 2008, respectivamente. Nesses estudos, os autores concluíram, entre outros aspectos, que (a) existe uma forte rede de instituições nacionais e pesquisadores locais tratando do tema; (b) há um avanço no recurso às referências bibliográficas de autores brasileiros em relação aos estrangeiros; (c) predominância de trabalhos tratando das competências individuais na área de recursos humanos e de competências organizacionais nos trabalhos na área de estratégia $\mathrm{e}$ inovação; (d) predomínio de estudos de casos voltados à aplicação, com foco em uma ou duas empresas; e (e) poucas foram as pesquisas de cunho quantitativo ou que se propuseram a cobrir uma amplitude maior de organizações.

Além de estudos mais voltados para a questão das competências em geral, observase nas publicações brasileiras a presença de estudos que relacionam a questão das competências com os profissionais de administração, em processo de formação e/ou já formados. Esses estudos tiveram como proposta de pesquisa investigar aspectos como (a) a relação entre a identidade do administrador profissional e a competência tendo como principais fontes de informações a pesquisa nacional coordenada pelo Conselho Federal de Administração (CFA) (LACRUZ; VILLELA, 2007); (b) a percepção dos representantes da comunidade que interage no processo de capacitação de administradores e/ou egressos do curso de administração sobre as competências profissionais do administrador, analisando comparativamente a necessidade do mercado de trabalho e a formação dos administradores (ZAGO; SOUZA; BEZERRA, 2007); (c) as opiniões dos discentes de administração sobre as competências adquiridas no curso de administração (GODOY; ANTONELLO, 2009); e (d) percepção de discentes e docentes do curso de administração acerca das competências docentes (NOGUEIRA; BASTOS, 2012).

Diante de tal cenário de publicações sobre o tema competências e sobre a relação entre as competências e a atuação dos profissionais em administração, o presente estudo se coloca como uma via para preencher as lacunas deixadas por esses estudos. Enquanto os estudos anteriores 
focalizaram mais a educação formal, esta pesquisa abordou a educação plena envolvendo a educação informal, não formal e formal (GOHN, 2006). No que tange as fontes de informações, enquanto os estudos anteriores tiveram como fonte de informações pesquisa documental (pesquisa do CFA), discentes e docentes de cursos de administração e comunidade que interage no processo de capacitação de administradores e/ou egressos do curso de administração, esta pesquisa abordou o ponto de vista dos administradores inscritos em órgão de classe que habilita os egressos ao exercício efetivo da profissão e a prática das competências aprendidas ao longo da vida. Sobre as abordagens metodológicas observou-se nos estudos anteriores o predomínio de pesquisa de cunho qualitativo, via estudo de caso (RUAS et al., 2010), sendo que, de forma diferente, este estudo utilizou a abordagem de pesquisa quantitativa, cuja população foi de 10.488 administradores, portanto, cobrindo uma amplitude maior de indivíduos.

É com fundamento nas reflexões teóricas e empíricas aqui apresentadas, que surge o problema de pesquisa que norteou o estudo: Qual é o ponto de vista dos administradores em relação ao processo de formação das competências requeridas pelo mercado de trabalho? Objetiva-se com a pesquisa identificar e analisar a visão dos administradores inscritos no CRA/ES acerca do processo de formação de competências que são requeridas pelo mercado de trabalho. Definiu-se como objetivos específicos: (1) identificar as competências exigidas pelo mercado de trabalho; (2) identificar a contribuição da formação educacional em nível superior (educação formal) no desenvolvimento de competências exigidas pelo mercado de trabalho; (3) identificar a contribuição da experiência de vida (educação informal e não formal) no desenvolvimento de competências exigidas pelo mercado de trabalho; e (4) analisar comparativamente a contribuição da formação educacional em nível superior e da experiência de vida no processo de formação de competências.

O artigo está estruturado em quatro seções além da presente introdução. $\mathrm{Na}$ segunda, apresenta-se a fundamentação teórica; na terceira seção encontram-se os procedimentos metodológicos da pesquisa; na quarta, expõe-se a apresentação e a discussão dos resultados da pesquisa; e na quinta e última seção as conclusões da pesquisa. 


\section{FUNDAMENTAÇÃO TEÓRICA}

Nesta seção discutem-se fundamentalmente dois aspectos essenciais: (a) a formação educacional e profissional do administrador; e (b) o conceito de competência de forma geral e, em específico, a relação entre a competência e a profissão do administrador.

\subsection{Formação educacional e profissional} do administrador

A literatura acerca da formação educacional e profissional do administrador é caracterizada entre outros fatores pela: preocupação com a discrepância entre a formação acadêmica e as exigências do mercado (MINTZBERG, 1986; 2006; ANTONELLO; RUAS, 2005; BORBA; FAGGION; SILVEIRA, 2005); e a carência de trabalhos empíricos que avaliem a efetividade da formação educacional e profissional do administrador (ANTONELLO; RUAS, 2005). No que tange a avaliação da formação de executivos, Mintzberg (1986; 2006) afirma que as escolas de administração foram efetivas na formação de especialistas (cientistas administrativos e pesquisadores organizacionais, entre outros), embora, a maioria das escolas não tenha, de fato, preparado executivos.

No entendimento de Mintzberg (2006), a efetividade na formação de executivos somente será alcançada quando o treinamento prático ocupar posição importante ao lado do conhecimento cognitivo. Visto de outra forma, para o autor, as escolas de negócios, ao negligenciarem os aspectos práticos da atividade gerencial, estão deixando de formar executivos de fato. Em parte, o que o autor defende é que a formação educacional e profissional não pode contemplar apenas aspectos da educação formal, mas contemplar outros aspectos que estejam relacionados à vivência e à experiência prática que são alcançados por meio de outras modalidades de educação, como por exemplo, a formação não formal e informal.

Segundo Gohn (2006) e Palhares (2009) a educação abrange três modalidades distintas, porém complementares: educação informal, não formal e formal. Para Gohn (2006), a discussão acerca dessas modalidades é fecunda e é comum estabelecer uma comparação entre elas, bem como confundir as características individuais de cada uma delas. Objetivando esclarecer as características de cada uma dessas modalidades, a autora estabelece seis 
critérios de diferenciação: (a) quem é o educador; (b) espaço físico territorial onde ocorrem os atos e os processos educativos; (c) como se educa, em que situação e contexto; (d) a finalidade ou objetivo; (e) os principais atributos; e (f) os resultados esperados.

A educação informal é aquela em que os indivíduos aprendem durante o processo de socialização, na família, na igreja, entre os amigos. Nessa modalidade, o agente educador são os pais, a família, os amigos, etc. Aqui, a educação possui espaços educativos demarcados por valores e culturas próprias, referências de nacionalidade, localidade, etnia entre outros fatores sociais que fornecem uma noção de pertencimento e sentimentos herdados. A educação opera em ambientes espontâneos, onde as relações sociais se desenvolvem segundo gostos, preferências ou pertencimentos herdados. A finalidade dessa modalidade é socializar os indivíduos, desenvolver hábitos, atitudes e comportamentos, entre outros, segundo os valores e crenças do grupo a que o indivíduo pertence. Ela caracteriza-se por não ser organizada, os conhecimentos não são sistematizados e são repassados a partir de práticas e experiências anteriores. Os resultados da educação informal não são esperados, eles simplesmente acontecem a partir do senso comum dos indivíduos que orienta suas formas de pensar e agir espontaneamente (GOHN, 2006).

A educação não formal é aquela que se aprende no "mundo da vida", via os processos de compartilhamento de experiências, principalmente em espaços e ações coletivas cotidianas. Nessa modalidade, o grande educador é o "outro", aquele sujeito com quem se interage ou se integra. Aqui os espaços educativos localizam-se em territórios que acompanham as trajetórias de vida dos grupos e dos indivíduos, fora das escolas, em ambientes e situações interativas construídos coletivamente, segundo as diretrizes dos grupos, em que a intencionalidade é um elemento importante de diferenciação das demais modalidades. A finalidade dessa modalidade é capacitar os indivíduos a se tornarem cidadãos do (e no) mundo. Seus objetivos se constroem em processos interativos, gerando um processo educativo (um modo de educar surge como resultado do processo voltado para os interesses e as necessidades coletivas). Ela se caracteriza por atuar sobre os aspectos subjetivos do grupo; trabalhar e formar a cultura política do grupo; desenvolver laços de pertencimento; contribuir com a construção 
da identidade coletiva do grupo. Essa modalidade educacional tem como resultados, processos relacionados à consciência e à organização de como agir em grupos coletivos; construção, desconstrução e reconstrução de concepções de mundo e sobre o mundo; contribuição para o desenvolvimento de um sentimento de identidade com uma dada comunidade; entre outros (GOHN, 2006).

A educação formal é aquela desenvolvida nas instituições educacionais regulamentadas por lei, credenciadas por órgãos oficiais de educação, certificadoras, organizadas segundo diretrizes curriculares nacionais com conteúdos previamente demarcados, tendo a figura do professor como o principal educador. Os espaços estão relacionados ao território da escola e das instituições educacionais. Esse tipo de educação pressupõe ambientes normatizados, com regras e padrões comportamentais definidos previamente. A sua finalidade, que está relacionada ao processo de ensino e aprendizagem de conteúdos historicamente sistematizados e normatizados por normas jurídicas abrange, entre outros aspectos, formar o indivíduo como um cidadão ativo; desenvolver habilidades e competências diversas; desenvolver a criatividade, a percepção e a motricidade. Ela caracteriza-se por requerer tempo, local específico, pessoal especializado, organização de vários tipos (curricular, por exemplo), sistematização sequencial de atividades, disciplina, normatização, órgãos superiores, entre outros. Como resultado, espera-se que haja um aprendizado efetivo, além da certificação e da titulação que capacitam os indivíduos a seguirem para graus ou níveis educacionais formais mais avançados (GOHN, 2006).

Especificamente em relação à educação formal do administrador, destacase que o ensino universitário de administração no Brasil somente foi alavancado após a Revolução de 1930, com a criação de cursos para atender as demandas do mercado produtivo e com o surgimento, nas décadas de 1930 e de 1940, de instituições como o Instituto de Organização Racional do Trabalho (IDORT), o Serviço Nacional de Aprendizagem Comercial (SENAC) e o Serviço Nacional de Aprendizagem Industrial (SENAI) (NICOLINI, 2003; MURARI; HELAL, 2009). Desde a sua origem até os dias atuais, a educação superior formal em administração desenvolveu-se em ritmo acelerado, fazendo com que o curso tivesse, em 2010, o maior quantitativo de matrículas entre os cursos superiores de graduação nas 
modalidades presencial e a distância e nos graus acadêmicos do tipo bacharelado, licenciatura e tecnológico (INEP, 2011). Essa condição de curso com maior quantitativo de matrículas na educação superior brasileira vem se mantendo nos resultados do censo da educação superior brasileira divulgado pelo INEP.

A regulamentação da profissão do administrador ocorreu com a publicação da Lei n. ${ }^{\circ}$ 4.769, de 9 de setembro de 1965. Além de criar a categoria profissional e dispor sobre o exercício profissional do administrador, essa lei criou um conjunto de autarquias compostas pelo CFA e os CRA, cujas finalidades, entre outras são a de orientar e disciplinar o exercício da profissão de administrador; fiscalizar o exercício da profissão de administrador; e organizar e manter o registro de administrador.

A expansão dos cursos superiores em administração ocorreu em meio às preocupações de natureza qualitativa, sobretudo com a questão curricular desses cursos. Primeiramente, a promulgação da Lei de Diretrizes e Bases da Educação Nacional (LDB) de 1961 e, posteriormente, da Lei de Reforma Universitária de 1968 estabeleceram que o então Conselho Federal de Educação (CFE) fixasse os currículos mínimos para os cursos de graduação. A proposta da época era estabelecer um patamar uniforme entre cursos de instituições diferentes. Essa orientação sofreu alterações com a promulgação da Lei $\mathrm{n}^{\circ} 9.131$ de 1995 e mais tarde da LDB de 1996, que conferiu à Câmara de Educação Superior (CES) do Conselho Nacional de Educação (CNE) a competência para elaborar o projeto de Diretrizes Curriculares Nacionais (DCN). Diferentemente do que ocorria com o currículo mínimo, as DCN deveriam ser, entre outros fatores, constituídas em orientações para a elaboração dos currículos e assegurar a flexibilidade e a qualidade da formação oferecida aos discentes.

No caso do curso de graduação em administração as DCN foram estabelecidas por meio da Resolução CNE/CES no 4, de 13 de julho de 2005. Essa DCN, de forma inovadora para o período de sua publicação, definiu, entre outros aspectos, que o curso de graduação em administração deve possibilitar a formação profissional que revele um conjunto de competências e habilidades mínimas, das quais se podem destacar a capacidade para reconhecer e definir problemas, equacionar soluções e pensar estrategicamente; desenvolver expressão e comunicação compatíveis com o 
exercício profissional; e desenvolver raciocínio lógico, crítico e analítico.

Observa-se nesse contexto de expansão da educação formal do curso de graduação em administração dois aspectos centrais e complementares. Primeiro que, conforme aponta Nicolini (2003) a regulamentação do ensino superior em administração foi uma consequência da regulamentação profissional, ou seja, a finalidade de cursar a graduação está diretamente relacionada à obtenção do diploma, que habilita o diplomado a prática e o exercício profissional. O segundo aspecto, diz respeito ao fato de que, conforme defende Gohn (2006), a educação formal se caracteriza por requerer normatização e articulação de organismos institucionais que forneçam a organização e a sistematização necessárias ao seu funcionamento. É o que ocorre no relacionamento entre o Ministério da Educação (MEC) que representa a área educacional e o CFA que representa a classe profissional, que, em conjunto, viabilizam a educação formal em administração ao discutirem as diretrizes curriculares, a carga horária, o conjunto de competências e habilidades mínimas, entre outros aspectos.

\subsection{O conceito de competência e a profissão do administrador}

O debate sobre competência iniciou entre psicólogos e administradores nos Estados Unidos, marcado pela publicação, em 1973, do artigo intitulado "Testing for competence rather than intelligence" de David C. McClelland. A noção de competência surge a partir da necessidade de encontrar um método para avaliar as pessoas para desempenharem de forma superior determinada tarefa ou situação pertinentes a um cargo (FLEURY; FLEURY, 2001). Nesta perspectiva inaugurada por McClelland (1973) e identificada como abordagem anglo-saxônica sobre competência, "a gestão por competência é apenas um rótulo mais moderno para administrar uma realidade organizacional ainda fundada nos princípios do taylorismo/fordismo" (FLEURY; FLEURY, 2001, p.185). Essa abordagem se propõe a avaliar as competências a partir das necessidades organizacionais e do mercado de trabalho, estando, então, a competência relacionada aos descritores de desempenho requeridos pela organização (SANT'ANNA, 2008).

$\mathrm{Na}$ França, diferentemente, as discussões sobre competência surgem da avaliação sobre o descompasso entre a 
educação e as necessidades do mundo do trabalho. Essa forma de conceber a competência se apresenta como uma nova abordagem sobre o tema, comumente identificada como abordagem francesa das competências (FLEURY; FLEURY, 2001; SANT'ANNA, 2008). Dois autores franceses se destacam nesta abordagem: Philippe Zarifian e Guy Le Boterf.

Para Zarifian (2001) são três as mutações principais no mundo do trabalho que justificam a emergência do modelo de competência, são elas: (a) a noção de incidente, aquilo que não está programado, que ocorre de forma imprevista, vindo causar alteração no funcionamento normal do sistema produtivo, e que exige que as pessoas estejam sempre mobilizando recursos para resolver novas situações; (b) a noção de comunicação, o que implica que as pessoas compreendam a si mesmas e os outros para poderem compartilhar objetivos e normas organizacionais; e (c) a noção de serviços, que coloca como ponto central em todas as atividades a necessidade de atender um cliente seja ele interno ou externo à organização. O trabalho deixa de ser o conjunto de tarefas associadas descritivamente ao cargo e passa a ser concebido como a mobilização das competências do indivíduo em uma situação profissional cada vez mais mutável e complexa.

A competência, então, para Zarifian (2001) articula três questões essenciais: (a) iniciativa e responsabilidade que o indivíduo precisa assumir em uma situação profissional; (b) inteligência prática, que envolve os conhecimentos adquiridos e a transformação dos mesmos de acordo com a situação vivenciada; e (c) capacidade de mobilizar as pessoas para compartilharem os desafios e assumirem responsabilidades. Dessa forma, o conceito de competência é concebido como "a tomada de iniciativa e o assumir de responsabilidade do indivíduo sobre problemas e eventos que ele enfrenta em situações profissionais" (ZARIFIAN, 2003, p.139).

Le Boterf (2003) afirma que junto com o conceito de competência, que ganhou importância no decorrer dos anos 80, emerge a noção de profissionalismo. Para o autor, as competências articulam três eixos formativos (a pessoa, sua biografia e socialização; a formação educacional e a experiência profissional) que representam um conjunto de aprendizagens sociais e comunicacionais. Ao serem ativadas, as competências se aproximam da noção de profissionalismo defendida por Le Boterf (2003). Para isso, a ativação das competências articula três 
dimensões, quais sejam: (a) dos recursos disponíveis, envolvendo os conhecimentos, o saber-fazer, as capacidades cognitivas, as competências comportamentais, entre outras, que são passíveis de serem mobilizadas para a ação; (b) das ações e dos resultados, em termos das práticas profissionais e do desempenho; e (c) da reflexibilidade, ou seja, do distanciamento em relação às duas dimensões anteriores para avaliar todo o processo. Nesse sentido, profissional é aquele que domina suas competências e as articula com a finalidade de adaptar-se as mudanças do mercado de trabalho. Do profissional é esperado que saiba administrar a complexidade das situações, para isso ele deve: saber agir com pertinência, saber mobilizar saberes e conhecimentos em um contexto profissional, saber integrar ou combinar saberes múltiplos e heterogêneos, saber transpor, saber aprender, saber aprender a aprender e saber envolver-se.

Com o objetivo de sistematizar o conceito de competência Fleury e Fleury (2001) articularam os conceitos apresentados por estes dois autores. Fleury e Fleury (2001) definem competência como "um saber agir responsável e reconhecido que implica mobilizar, integrar, transferir conhecimentos, recursos e habilidades, que agreguem valor econômico à organização e valor social ao indivíduo" (FLEURY; FLEURY, 2001, p. 188).

A noção de competência explorada por esses autores apresenta um aspecto importante, pois deixa explícito o ganho por parte da organização no desenvolvimento das competências. Segundo os autores, os trabalhadores ao desenvolverem competências, além de investirem em si mesmos, contribuem para o sucesso da organização (FLEURY; FLEURY, 2001). Outro autor brasileiro que procura sistematizar o conceito de competência é Dutra (2001). Este autor afirma que para compreender o conceito de competência é necessário entender o conceito de entrega que é aquilo que a pessoa tem a possibilidade e deseja entregar à organização, são os atos e as realizações das pessoas, que não necessariamente estão descritos em suas funções ou atividades. Segundo Dutra (2001), o saber agir responsável e reconhecido estabelecido na definição de competência sugerido por Fleury e Fleury (2001) define bem o conceito de entrega. Considerando a capacidade de entrega das pessoas tem-se um panorama mais adequado de avaliação para nortear o desenvolvimento e estabelecer recompensas nas organizações. 
Sant'Anna; Moraes e Kilimnik (2005) apoiados na compreensão de competência como resultante de múltiplos saberes (saber fazer; saber agir; saber ser), realizou uma revisão teórica das abordagens anglo-americanas (SPENCER; SPENCER, 1993; BOYATZIS, 1982; entre outros) e francesas (LE BOTERF, 1994; ZARIFIAN, 2001; entre outros) com a finalidade de identificar as competências individuais mais enfaticamente requeridas pelas organizações contemporâneas. Como resultado dessa revisão, foram identificadas quinze competências: (1) domínio de novos conhecimentos técnicos associados ao exercício do cargo ou função ocupada; (2) capacidade de aprender rapidamente novos conceitos e tecnologias; (3) criatividade; (4) capacidade de inovação; (5) capacidade de comunicação; (6) capacidade de relacionamento interpessoal; (7) capacidade de trabalhar em equipes; (8) autocontrole emocional; (9) visão de mundo ampla e global; (10) capacidade de lidar com situações novas e inusitadas; (11) capacidade de lidar com incertezas e ambiguidades; (12) iniciativa de ação e decisão; (13) capacidade de comprometer-se com os objetivos da organização; (14) capacidade de gerar resultados efetivos; e (15) capacidade empreendedora. Essas quinze competências constituíram o instrumento de coleta de dados cujas escalas foram validadas e testadas empiricamente nos estudos realizados por Kilimnik; Sant'anna e Luz (2004) e Sant'anna; Moraes e Kilimnik (2005).

Para fins deste estudo, optou-se por utilizar a abordagem francesa de competência, mais especificamente, optou-se pela perspectiva de Le Boterf (2003), visto que ela demostra ser adequada e coerente com a proposta de pesquisa aqui empreendida. Essa adequação e coerência encontram fundamento no fato de que o conceito de competência de Le Boterf (2003) permite articular, simultaneamente, as três modalidades de educação apontadas por Gohn (2006) e os três níveis de compreensão da competência apontados por Fleury e Fleury (2001). Além disso, optou-se por utilizar as quinze competências identificadas, validadas e testadas empiricamente por Kilimnik; Sant'anna e Luz (2004) e Sant'anna; Moraes e Kilimnik (2005).

\section{ASPECTOS METODOLÓGICOS}

Metodologicamente o estudo caracteriza-se como um estudo descritivo-quantitativo por meio do método de pesquisa survey interseccional (BABBIE, 2005). O público- 
alvo foi administradores inscritos no CRA/ES cuja população totalizava na época da coleta de dados 10.488 inscritos. Considerando que a população é do tipo finita, o grau de confiança de $95 \%$ e a margem de erro de 6,00, o tamanho da amostra requerido para permitir a generalização dos resultados foi de 261 inscritos (BABBIE, 2005; LUCHESA; CHAVES NETO, 2011).

Os dados foram coletados por meio de questionário eletrônico autopreenchido, pré-testado, validado, aplicado via internet e submetido aos administradores pertencentes à amostra da população alvo da pesquisa. $\mathrm{O}$ questionário foi constituído por dois blocos: Bloco I: com 14 questões que caracterizam o perfil pessoal e profissional do respondente; e Bloco II: com 45 questões diretamente ligadas ao objetivo da pesquisa.

O Bloco II do questionário foi elaborado com base no instrumento e nas escalas validadas e testadas empiricamente por Kilimnik; Sant'anna e Luz (2004) e Sant'anna; Moraes e Kilimnik (2005) sobre as quinze competências individuais mais enfaticamente requeridas pelas organizações contemporâneas. $\mathrm{O}$ coeficiente de consistência interna do instrumento, medido por meio do coeficiente alfa de Cronbach, foi de 0,93. Ressalta-se que, no instrumento original, para a mensuração das competências individuais requeridas, os autores utilizaram a escala Likert de 11 (onze) pontos. No presente estudo, a escala original foi adaptada, sendo constituída de 5 (cinco) pontos, variando entre $1=$ não contribui/não exigido e 5=maior grau de contribuição/exigência. Utilizou-se a escala para três finalidades distintas, quais sejam, mensurar: (a) o nível exigido das competências pelo mercado de trabalho; (b) o grau de contribuição da formação educacional de nível superior no desenvolvimento das competências requeridas pelo mercado de trabalho; e (c) o grau de contribuição da experiência de vida na formação das competências. Essas três escalas obtiveram, respectivamente, o coeficiente alfa de Cronbach de 0,92, 0,95 e 0,92. Dessa forma, a escala adaptada manteve-se fidedigna, uma vez que o limite mínimo sugerido por Mesquita (2010) é de 0,70. As quinze competências investigadas no Bloco II do questionário são as apresentadas no Quadro 1 a seguir. 
Quadro 1 - As quinze competências requeridas pelas organizações contemporâneas

\begin{tabular}{|l|l|l|l|}
\hline \multicolumn{3}{|c|}{ Competências Individuais } \\
\hline 1. & $\begin{array}{l}\text { Capacidade de aprender rapidamente novos } \\
\text { conceitos e tecnologias }\end{array}$ & 9. & Capacidade de inovação \\
\hline 2. & Capacidade de trabalhar em equipes & 10. & Capacidade de relacionamento interpessoal \\
\hline 3. & Criatividade & 11. & Iniciativa de ação e decisão \\
\hline 4. & Visão de mundo ampla e global & 12. & Autocontrole emocional \\
\hline 5. & $\begin{array}{l}\text { Capacidade de comprometer-se com os objetivos da } \\
\text { organização }\end{array}$ & 13. & Capacidade empreendedora \\
\hline 6. & Capacidade de comunicação & 14. & Capacidade de gerar resultados efetivos \\
\hline 7. & Capacidade de lidar com incertezas e ambiguidades & 15. & $\begin{array}{l}\text { Capacidade de lidar com situações novas e } \\
\text { inusitadas }\end{array}$ \\
\hline 8. & $\begin{array}{l}\text { Domínio de novos conhecimentos técnicos } \\
\text { associados ao exercício do cargo ou função ocupada }\end{array}$ & & \\
\hline
\end{tabular}

Fonte: Kilimnik; Sant'anna e Luz (2004) e Sant'anna; Moraes e Kilimnik (2005).

Foi realizado o pré-teste do questionário em duas turmas do curso de Administração da Universidade Federal do Espírito Santo (UFES), totalizando 40 participantes. Os dados coletados nessa fase, não foram utilizados na pesquisa, já que o objetivo do pré-teste é avaliar o instrumento em termos de dificuldades de compreensão, estimativas de tempo, etc., visando melhorálo (BABBIE, 2005). Durante a aplicação do questionário foi feita a contagem do tempo gasto pelos respondentes, assim como ouvidas as dúvidas e sugestões dos participantes. Em sequência foi feita a análise e as alterações necessárias. Foram feitas alterações no Bloco I do questionário, ampliando o número de questões com vistas a torna-lo mais abrangente.

Após feitas as modificações necessárias, $\mathrm{o}$ questionário foi disponibilizado na internet em site específico pelo período de três meses. O link do site foi enviado aos administradores inscritos no CRA/ES, pelo próprio órgão, através de correio eletrônico. Antes de responder o questionário, foram fornecidas informações aos administradores sobre os objetivos da pesquisa, assim como assegurado que a participação na pesquisa era voluntária e que todas as informações coletadas são estritamente confidenciais, garantindo $\mathrm{o}$ anonimato. Em média, o tempo de resposta do questionário foi de 15 minutos.

Inicialmente, foram enviados questionários para todos os 10.488 administradores inscritos no CRA/ES. Obteve-se como retorno 528 questionários. Deste total foram eliminados os questionários com respostas incompletas. Assim obteve-se um total de 358 questionários válidos, que se configurou no tamanho da amostra da pesquisa. Considerando que o tamanho da amostra requerido para esse tipo de população foi de 
261 inscritos, o tamanho obtido permitiu a generalização dos resultados para toda a população (BABBIE, 2005).

Para tratamento estatístico dos dados, fez-se uso do pacote estatístico Statistical Package for the Social Sciences - SPSS versão 19, no qual foram realizadas as seguintes análises estatísticas dos dados: análise descritiva, teste qui-quadrado, teste $t$ emparelhado, ANOVA e análise da confiabilidade das escalas, por meio do cálculo do coeficiente alfa de Cronbach.

\section{APRESENTAÇÃO E DISCUSSÃO DOS RESULTADOS}

Nesta seção serão apresentados os resultados subdivididos em seis tópicos: (a) perfil dos respondentes (administradores inscritos no CRA/ES); (b) as competências requeridas pelo mercado de trabalho; (c) contribuição da formação educacional de nível superior no desenvolvimento das competências requeridas pelo mercado de trabalho; (d) contribuição da experiência de vida no desenvolvimento das competências requeridas pelo mercado de trabalho; (e) formação de competências; e, por fim, (f) discussão dos resultados.

\subsection{Perfil dos respondentes}

Os respondentes são em sua maioria, naturais do Espírito Santo (71,23\%), do sexo masculino $(56,15 \%)$ e tem registro no CRA entre 1 ano até 5 anos $(50,84 \%)$. Em relação à faixa etária, destacam-se as faixas de 21 anos até 30 anos $(37,15 \%)$ e de 31 anos até $40 \operatorname{anos}(33,80 \%)$. No que tange a pósgraduação constatou-se uma divisão entre os que não possuem pós-graduação $(50,84 \%)$ e os que possuem pós-graduação (lato ou stricto sensu) $(49,16 \%)$. Em relação ao cargo ocupado, 35,20\% dos respondentes ocupam posição de gestão (coordenador/supervisor/gerente), 21,23\% cargos de nível técnico operacional (auxiliar/assistente) e 17,32\% cargos de nível técnico especializado (analista/especialista). Quanto ao tipo de empresa nota-se a predominância de empresas privadas $(64,53 \%)$, atuantes no setor de comércio e serviços $(55,87 \%)$. Os resultados do questionário sóciodemográfico estão na Tabela 1 a seguir. 
Tabela 1 - Distribuição dos participantes do estudo $(\mathrm{n}=358)$

\begin{tabular}{|c|c|c|}
\hline \multirow{2}{*}{ Variáveis } & \multicolumn{2}{|c|}{ Observações } \\
\hline & $\mathbf{N}$ & $\%$ \\
\hline \multicolumn{3}{|l|}{ Naturalidade } \\
\hline Espírito Santo & 255 & 71,23 \\
\hline Outros estados da região sudeste & 73 & 20,39 \\
\hline Demais estados & 17 & 4,75 \\
\hline Não responderam & 13 & 3,63 \\
\hline \multicolumn{3}{|l|}{ Sexo } \\
\hline Masculino & 201 & 56,15 \\
\hline Feminino & 157 & 43,85 \\
\hline \multicolumn{3}{|l|}{ Faixa Etária } \\
\hline De 21 anos até 30 anos & 133 & 37,15 \\
\hline De 31 anos até 40 anos & 121 & 33,80 \\
\hline De 41 anos até 50 anos & 64 & 17,88 \\
\hline Mais de 51 anos & 40 & 11,17 \\
\hline \multicolumn{3}{|l|}{ Registro no CRA } \\
\hline Menos de 1 ano & 67 & 18,72 \\
\hline De 1 ano até 5 anos & 182 & 50,84 \\
\hline De 6 anos até 10 anos & 76 & 21,23 \\
\hline Mais de 11 anos & 33 & 9,22 \\
\hline \multicolumn{3}{|l|}{ Pós-graduação } \\
\hline Possui pós-graduação (especialização, mestrado, doutorado) & 176 & 49,16 \\
\hline Não se aplica & 182 & 50,84 \\
\hline \multicolumn{3}{|l|}{ Cargo ocupado } \\
\hline $\begin{array}{l}\text { Direção (diretor, vice-diretor, presidente, vice-presidente, } \\
\text { superintendente) }\end{array}$ & 34 & 9,50 \\
\hline Posição de gestão (coordenador, supervisor, gerente) & 126 & 35,20 \\
\hline Técnico especializado (analista especialista) & 62 & 17,32 \\
\hline Técnico operacional (auxiliar, assistente) & 76 & 21,23 \\
\hline Profissional liberal & 22 & 6,15 \\
\hline Outros & 38 & 10,61 \\
\hline \multicolumn{3}{|l|}{ Tipo da empresa } \\
\hline Mista (público-privada) & 29 & 8,10 \\
\hline Privada & 231 & 64,53 \\
\hline Pública & 84 & 23,46 \\
\hline Sem fins lucrativos & 14 & 3,91 \\
\hline \multicolumn{3}{|l|}{ Ramo de atuação da empresa } \\
\hline Comércio e Serviços & 200 & 55,87 \\
\hline Indústria & 75 & 20,95 \\
\hline Órgão Público & 83 & 23,18 \\
\hline
\end{tabular}

Fonte: Dados da pesquisa.

Com a finalidade de testar a associação entre as variáveis demográficas aplicou-se o teste do qui-quadrado e constatou-se que tanto o sexo $(p=0,006)$ quanto à idade $(\mathrm{p}=0,000)$ são fatores determinantes em relação ao cargo ocupado. Em relação ao sexo, apesar de em sua maioria homens e mulheres ocuparem cargos de gestão, observa-se que os cargos de direção são ocupados na maioria por homens $(70,59 \%)$, ao passo que os cargos operacionais são ocupados em maior percentual pelas mulheres $(61,84 \%)$. Já quanto à faixa etária, tem-se que os cargos 
de direção são ocupados por $38,29 \%$ dos respondentes com idade maior que 51 anos e os cargos operacionais por $57,89 \%$ dos que estão na faixa etária de 21 anos até 30 anos.

\subsection{Competências requeridas pelo mercado de trabalho}

Com relação à distribuição de frequência das respostas obtidas em relação às competências requeridas pelo mercado de trabalho que se encontra na Tabela 2 a seguir, percebe-se uma concentração de respostas nos últimos pontos de escala (4 e
5), que pode ser observado pelo cálculo da média que resultou no valor de 4,41. Os resultados indicam que, do ponto de vista dos respondentes, as quinze competências individuais possuem um elevado grau de exigência por parte do mercado de trabalho. Dentre elas, as três competências com maior percentual atribuído foram: capacidade de trabalhar em equipes (76\%); capacidade de comprometer-se com os objetivos da organização $(72,1 \%)$; e capacidade de gerar resultados efetivos $(65,9 \%)$.

Tabela 2 - Ponto de vista dos administradores quanto às competências requeridas pelo mercado de trabalho (em \%)

\begin{tabular}{|c|c|c|c|c|c|c|c|c|}
\hline \multirow{2}{*}{ Competência Individual } & \multirow{2}{*}{ Média } & \multirow{2}{*}{$\begin{array}{l}\text { Desvio } \\
\text { Padrão }\end{array}$} & \multicolumn{5}{|c|}{ Escala } & \multirow{2}{*}{ Total } \\
\hline & & & 1 & 2 & 3 & 4 & 5 & \\
\hline Aprender novos conceitos e tecnologias & 4,55 & 0,69 & 0,3 & 0,8 & 7,0 & 27,1 & 64,8 & 100 \\
\hline Trabalho em equipes & 4,70 & 0,61 & 0,3 & 0,8 & 3,9 & 19,0 & 76,0 & 100 \\
\hline Criatividade & 4,27 & 0,80 & 0,6 & 0,8 & 16,2 & 35,5 & 46,9 & 100 \\
\hline Visão de mundo ampla e global & 4,18 & 0,84 & 0,3 & 1,7 & 20,9 & 34,1 & 43,0 & 100 \\
\hline Comprometimento organizacional & 4,65 & 0,64 & 0,6 & 0,8 & 3,4 & 23,2 & 72,1 & 100 \\
\hline Comunicabilidade & 4,48 & 0,73 & 0,6 & 0,8 & 8,1 & 31,3 & 59,2 & 100 \\
\hline Lidar com incertezas e ambiguidades & 4,15 & 0,82 & 0,6 & 2,8 & 15,1 & 44,4 & 37,2 & 100 \\
\hline Domínio de novos conhecimentos & 4,37 & 0,81 & 0,8 & 1,7 & 11,2 & 32,7 & 53,6 & 100 \\
\hline Inovação & 4,33 & 0,83 & 0,6 & 2,8 & 11,7 & 33,2 & 51,7 & 100 \\
\hline Relacionamento interpessoal & 4,53 & 0,72 & 0,3 & 1,1 & 8,1 & 26,5 & 64,0 & 100 \\
\hline Iniciativa de ação e decisão & 4,49 & 0,73 & 0,6 & 1,4 & 6,7 & 31,5 & 59,8 & 100 \\
\hline Autocontrole emocional & 4,35 & 0,87 & 1,7 & 1,7 & 11,5 & 30,2 & 55,0 & 100 \\
\hline Empreendedorismo & 4,04 & 0,96 & 1,7 & 5,3 & 17,9 & 37,2 & 38,0 & 100 \\
\hline Geração de resultados efetivos & 4,58 & 0,65 & 0,3 & 0,6 & 5,9 & 27,4 & 65,9 & 100 \\
\hline Lidar com novas situações & 4,42 & 0,74 & 0,6 & 0,8 & 9,2 & 35,2 & 54,2 & 100 \\
\hline
\end{tabular}

Fonte: Dados da pesquisa.

Foram efetuadas análises múltiplas de variância (ANOVA) para verificar a significância dos efeitos de cada uma das variáveis explicativas (sexo, faixa etária, cargo ocupado e tipo de empresa em que atua) sobre a variável dependente (média das 
respostas dos administradores em relação às competências individuais requeridas pelo mercado de trabalho). Constatou-se que apenas a variável faixa etária apresentou efeito significativo $(\mathrm{F}(2,777) ; \mathrm{p}=0,041)$, sendo o mesmo entre as faixas etárias de 21 até 30 anos e de 31 até 40 anos. Ou seja, os respondentes de 31 até 40 anos avaliam o mercado de trabalho como mais exigente que os de 21 até 30 anos.

Com a finalidade de esclarecer a diferença encontrada, realizou-se novamente o teste ANOVA, dessa vez para verificar a significância dos efeitos da variável independente (faixa etária) sobre cada uma das quinze competências avaliadas pelos administradores quanto à exigência do mercado de trabalho. Foram encontradas diferenças significativas em relação à competência autocontrole emocional $(\mathrm{F}(3,096) ; \quad \mathrm{p}=0,027)$ e a competência capacidade empreendedora $(\mathrm{F}(3,174)$; $\mathrm{p}=0,015)$. Com isso, constata-se que, para os respondentes de 31 até 40 anos as competências autocontrole emocional e capacidade empreendedora possuem maior grau de exigência por parte do mercado de trabalho.

\subsection{Contribuição da formação educacional de nível superior no desenvolvimento das competências requeridas pelo mercado de trabalho}

Em relação à contribuição da formação educacional superior (educação formal), a distribuição de frequência das respostas obtidas e apresentadas na Tabela 3 a seguir, permite verificar uma maior dispersão entre os pontos 3,4 e 5 da escala, que pode ser observado pelo cálculo da média que resultou no valor de 3,92. Vale destacar que as competências com maior percentual atribuído pelos respondentes são: capacidade de comprometer-se com os objetivos da organização $(46,6 \%)$; capacidade de trabalhar em equipes $(42,5 \%)$; e, com o mesmo percentual $(41,6 \%)$, visão de mundo ampla e global e iniciativa de ação e decisão. 
Tabela 3 - Ponto de vista dos administradores quanto à contribuição da formação educacional de nível superior no desenvolvimento das competências requeridas pelo mercado de trabalho (em \%)

\begin{tabular}{lcccccccc}
\multirow{2}{*}{ Competência Individual } & \multirow{2}{*}{ Média } & Desvio & \multicolumn{7}{c}{ Escala } & \multirow{2}{*}{ Total } \\
\cline { 6 - 8 } & & Padrão & $\mathbf{1}$ & $\mathbf{2}$ & $\mathbf{3}$ & $\mathbf{4}$ & $\mathbf{5}$ & \\
\hline Aprender novos conceitos e tecnologias & 3,97 & 1,03 & 2,5 & 5,9 & 21,5 & 32,4 & 37,7 & 100 \\
\hline Trabalho em equipes & 4,07 & 0,99 & 2,2 & 3,9 & 20,9 & 30,4 & 42,5 & 100 \\
\hline Criatividade & 3,75 & 1,15 & 5,0 & 10,1 & 21,2 & 31,8 & 31,8 & 100 \\
\hline Visão de mundo ampla e global & 4,14 & 0,91 & 1,4 & 3,9 & 15,4 & 37,7 & 41,6 & 100 \\
\hline Comprometimento organizacional & 4,11 & 1,04 & 2,8 & 4,7 & 17,6 & 28,2 & 46,6 & 100 \\
\hline Comunicabilidade & 4,05 & 0,98 & 0,8 & 7,0 & 20,1 & 30,7 & 41,3 & 100 \\
\hline Lidar com incertezas e ambiguidades & 3,74 & 1,08 & 3,9 & 8,9 & 24,3 & 34,9 & 27,9 & 100 \\
\hline Domínio de novos conhecimentos & 3,95 & 1,08 & 3,6 & 6,4 & 20,1 & 31,0 & 38,8 & 100 \\
\hline Inovação & 3,80 & 1,10 & 4,2 & 8,1 & 23,5 & 32,4 & 31,8 & 100 \\
\hline Relacionamento interpessoal & 4,00 & 1,03 & 2,0 & 7,3 & 19,8 & 30,7 & 40,2 & 100 \\
\hline Iniciativa de ação e decisão & 3,96 & 1,11 & 3,6 & 7,5 & 19,3 & 27,9 & 41,6 & 100 \\
\hline Autocontrole emocional & 3,56 & 1,26 & 8,9 & 11,5 & 23,2 & 27,7 & 28,8 & 100 \\
\hline Empreendedorismo & 3,87 & 1,13 & 4,2 & 7,5 & 23,2 & 27,7 & 37,4 & 100 \\
\hline Geração de resultados efetivos & 4,01 & 1,02 & 3,1 & 5,3 & 17,3 & 36,0 & 38,3 & 100 \\
\hline Lidar com novas situações & 3,87 & 1,12 & 4,7 & 6,7 & 21,5 & 31,3 & 35,8 & 100 \\
\hline Fonte: Dados da pesquisa & & & & & & &
\end{tabular}

Fonte: Dados da pesquisa.

Pretendendo verificar a possível relação entre as variáveis explicativas (sexo, faixa etária, cargo ocupado e tipo de empresa em que atua) e a média das respostas em relação às competências desenvolvidas na formação educacional de nível superior, aplicou-se o teste ANOVA e não foi constatada significância estatística para nenhuma das variáveis explicativas.

\subsection{Contribuição da experiência de vida} no desenvolvimento das competências requeridas pelo mercado de trabalho.

Analisando a Tabela 4 a seguir, que destaca a distribuição de frequência das respostas em relação à contribuição da experiência de vida (educação informal e não formal) no desenvolvimento das competências requeridas pelo mercado de trabalho, observa-se uma concentração de respostas nos últimos pontos de escala (4 e $5)$, que pode ser observado pelo cálculo da média que resultou no valor de 4,38. As competências individuais para as quais a experiência de vida mais contribuiu para o 
desenvolvimento foram: capacidade de trabalhar em equipes $(66,5 \%)$; capacidade de relacionamento interpessoal $(64,8 \%) ; \mathrm{e}$ capacidade de comprometer-se com os objetivos da organização $(64,2 \%)$.

Tabela 4 - Ponto de vista dos administradores quanto à contribuição da sua experiência de vida no desenvolvimento das competências requeridas pelo mercado de trabalho (em \%)

\begin{tabular}{|c|c|c|c|c|c|c|c|c|}
\hline \multirow{2}{*}{ Competência Individual } & \multirow{2}{*}{ Média } & \multirow{2}{*}{$\begin{array}{l}\text { Desvio } \\
\text { Padrão }\end{array}$} & \multicolumn{5}{|c|}{ Escala } & \multirow{2}{*}{ Total } \\
\hline & & & 1 & 2 & 3 & 4 & 5 & \\
\hline Aprender novos conceitos e tecnologias & 4,44 & 0,73 & 0,8 & 0,6 & 7,8 & 35,8 & 55,0 & 100 \\
\hline Trabalho em equipes & 4,55 & 0,75 & 0,8 & 1,7 & 5,9 & 25,1 & 66,5 & 100 \\
\hline Criatividade & 4,35 & 0,78 & 0,6 & 0,8 & 13,4 & 33,0 & 52,2 & 100 \\
\hline Visão de mundo ampla e global & 4,29 & 0,82 & 0,3 & 2,5 & 13,7 & 34,9 & 48,6 & 100 \\
\hline Comprometimento organizacional & 4,49 & 0,77 & 0,3 & 1,1 & 11,7 & 22,6 & 64,2 & 100 \\
\hline Comunicabilidade & 4,48 & 0,70 & 0,3 & 0,0 & 10,3 & 29,9 & 59,5 & 100 \\
\hline Lidar com incertezas e ambiguidades & 4,28 & 0,82 & 0,8 & 2,0 & 12,6 & 37,2 & 47,5 & 100 \\
\hline Domínio de novos conhecimentos & 4,25 & 0,86 & 1,1 & 2,8 & 12,6 & 36,6 & 46,9 & 100 \\
\hline Inovação & 4,25 & 0,87 & 0,8 & 3,1 & 14,5 & 33,8 & 47,8 & 100 \\
\hline Relacionamento interpessoal & 4,54 & 0,72 & 0,6 & 1,4 & 5,9 & 27,4 & 64,8 & 100 \\
\hline Iniciativa de ação e decisão & 4,45 & 0,78 & 0,6 & 1,7 & 9,5 & 28,8 & 59,5 & 100 \\
\hline Autocontrole emocional & 4,42 & 0,81 & 1,4 & 1,4 & 7,8 & 32,4 & 57,0 & 100 \\
\hline Empreendedorismo & 4,09 & 1,00 & 3,1 & 3,1 & 17,9 & 34,1 & 41,9 & 100 \\
\hline Geração de resultados efetivos & 4,40 & 0,77 & 0,6 & 2,0 & 8,4 & 35,2 & 53,9 & 100 \\
\hline Lidar com novas situações & 4,47 & 0,77 & 0,8 & 1,7 & 7,3 & 30,2 & 60,1 & 100 \\
\hline
\end{tabular}

Fonte: Dados da pesquisa.

Para verificar se há relação entre as variáveis explicativas (sexo, faixa etária, cargo ocupado e tipo de empresa em que atua) e a média das respostas em relação às competências desenvolvidas na experiência de vida, utilizou-se o teste ANOVA. Porém nenhuma significância estatística foi encontrada, o que leva a concluir que independente de variáveis como sexo, faixa etária, cargo ocupado e tipo de empresa em que atuam, os administradores avaliam de forma não discriminante o seu processo de formação das competências, considerando tanto a formação educacional de nível superior quanto à experiência de vida.

\subsection{Formação de competências}

Considerando que o foco do estudo foi o processo de formação de competências e que a mesma situa-se em três eixos: formação educacional, a experiência pessoal (sua biografia, socialização) e a experiência profissional (LE BOTERF, 2003), avaliou-se a contribuição desses eixos na formação das competências dos administradores. 
A partir do cálculo das médias das respostas obtidas para cada uma das quinze competências individuais requeridas pelo mercado de trabalho, comparou-se o grau de contribuição da instituição de nível superior e o grau de contribuição da experiência de vida. Para tal, foi realizado o teste $t$ emparelhado, procedimento utilizado para testar se há diferenças significantes entre as variâncias de amostras emparelhadas.

Tabela 5 - Distribuição da média da formação, média da experiência, diferença entre médias, teste $t$ e significância

\begin{tabular}{lccccc}
\multicolumn{1}{c}{ Competência Individual } & Formação & Experiência & $\begin{array}{c}\text { Diferença entre } \\
\text { Médias }\end{array}$ & $\boldsymbol{t}$ & $\mathbf{P}$ \\
\hline $\begin{array}{l}\text { Aprender novos conceitos e } \\
\text { tecnologias }\end{array}$ & 3,97 & 4,44 & $-0,466$ & $-7,525$ &, 000 \\
\hline Trabalho em equipes & 4,07 & 4,55 & $-0,478$ & $-8,222$ &, 000 \\
\hline Criatividade & 3,75 & 4,35 & $-0,601$ & $-9,700$ &, 000 \\
\hline Visão de mundo ampla e global & 4,14 & 4,29 & $-0,148$ & $-2,733$ &, 007 \\
\hline Comprometimento organizacional & 4,11 & 4,49 & $-0,383$ & $-6,403$ &, 000 \\
\hline Comunicabilidade & 4,05 & 4,48 & $-0,436$ & $-8,077$ &, 000 \\
\hline Lidar com incertezas e & 3,74 & 4,28 & $-0,545$ & $-8,754$ &, 000 \\
\hline ambiguidades & 3,95 & 4,25 & $-0,304$ & $-4,738$ &, 000 \\
\hline Domínio de novos conhecimentos & 3,80 & 4,25 & $-0,450$ & $-7,244$ &, 000 \\
\hline Inovação & 4,00 & 4,54 & $-0,545$ & $-9,655$ &, 000 \\
\hline Relacionamento interpessoal & 3,96 & 4,45 & $-0,486$ & $-7,714$ &, 000 \\
\hline Iniciativa de ação e decisão & 3,56 & 4,42 & $-0,863$ & $-12,100$ &, 000 \\
\hline Autocontrole emocional & 3,87 & 4,09 & $-0,221$ & $-3,415$ &, 001 \\
\hline Empreendedorismo & 4,01 & 4,40 & $-0,388$ & $-6,536$ &, 000 \\
\hline Geração de resultados efetivos & 3,87 & 4,47 & $-0,603$ & $-9,480$ &, 000 \\
\hline Lidar com novas situações & & & & & \\
\hline Fon & & & & \\
\hline
\end{tabular}

Fonte: Dados da pesquisa.

Conforme se pode observar na

Tabela 5 anterior, a média da contribuição da formação de nível superior (educação formal) é inferior à média da contribuição da experiência de vida (educação informal e não formal). A diferença entre essas duas médias mostra que a experiência de vida contribui mais do que a formação educacional de nível superior, sendo estatisticamente significativa $(\mathrm{p}<0,05)$ para todas as quinze competências avaliadas.

\subsection{Discussão}

Os resultados da pesquisa indicam que articulação entre o conceito de competência de Le Boterf (2003); as competências requeridas pelo mercado de trabalho (KILIMNIK; SANT'ANNA; LUZ, 2004; $\quad$ SANT'ANNA; MORAES; KILIMNIK, 2005); as três modalidades de educação apontadas por Gohn (2006); e os três níveis de compreensão da competência 
apontados por Fleury e Fleury (2001) foi efetiva em termos dos procedimentos de coleta e análise de dados.

Os dados revelaram que a maioria dos homens e mulheres ocupam cargos de gestão, sendo que nos cargos de direção há um predomínio de homens, enquanto que nos cargos operacionais há um predomínio de mulheres. Esses resultados são convergentes com o entendimento de Carli e Eagly (2001) de que a ocupação das mulheres em cargos de maior relevância na hierarquia das corporações mundiais ainda é baixa e somente ocorreu a partir da década de 1990. No contexto brasileiro as mulheres tiveram maior inserção no mercado de trabalho a partir da década de 1970 (OLIVEIRA, 2003; HELAL; NEVES; FERNANDES, 2007). Segundo Oliveira (2003) a inserção da mulher no espaço público do trabalho no ambiente gerencial ocorreu com a ocupação do cargo de secretária e, somente mais recentemente, ocupando o cargo de gerente.

Dados mais recentes sobre a presença da mulher no mercado de trabalho são apresentados pelo Departamento Intersindical de Estatística e Estudos Socioeconômicos (DIEESE) e indicam que $21,4 \%$ das mulheres ocupavam cargos de gestão em 2009 e que os percentuais de mulheres em cargos de alta administração como presidência, vice-presidência e diretoria eram respectivamente $12,6 \%$, $11,4 \%$ e $18,2 \%$ (DIEESE, 2011). Em estudo sobre empregabilidade gerencial, Helal; Neves e Fernandes (2007) identificaram que a despeito do aumento gradual da participação da mulher no mercado de trabalho gerencial, há a presença de preconceitos em relação a elas. Os autores também observaram que $o$ fato de ser homem proporciona o aumento na empregabilidade gerencial.

Em parte, esses baixos percentuais de participação das mulheres em cargos de alta administração podem ser explicados pela visão estereotipada, discriminatória e preconceituosa que restringe as possibilidades de acesso da mulher a esse nível hierárquico. Essa visão faz acreditar que o bom gestor deve possuir características próximas do gênero masculino, que é considerado como mais adequado para situações de controle e de chefia organizacionais. Além disso, os papéis e as responsabilidades sociais atribuídas às mulheres tornam mais difíceis a tarefa de conciliar o trabalho com a família (LOUREIRO; CARDOSO, 2008). Nesse contexto, as mulheres enfrentam uma situação adversa, marcada, de um lado pelo 
estereótipo masculino na gestão e, de outro, pelo estereótipo feminino no cuidado da família, visto que, cabe a ela o papel social de se dedicar simultaneamente ao trabalho e à família.

De forma geral, constatou-se que, do ponto de vista dos respondentes, as quinze competências individuais (KILIMNIK; SANT'ANNA; LUZ, 2004; SANT'ANNA; MORAES; KILIMNIK, 2005) possuem um elevado grau de exigência por parte do mercado de trabalho. Dentre elas, destacaram-se com maiores percentuais as competências capacidade de trabalhar em equipes, capacidade de comprometer-se com os objetivos da organização e capacidade de gerar resultados efetivos. Os resultados são convergentes com os achados de Sant'anna; Moraes e Kilimnik (2005) e ao conceito de competências. Nesse aspecto, os resultados indicam haver certo alinhamento com a noção de competência defendida por Fleury e Fleury (2001), uma vez que essas três competências individuais permitem o agir responsável e reconhecido no ambiente de trabalho capaz de agregar valor econômico para a organização e valor social para o indivíduo.

Analisando o ponto de vista dos respondentes na faixa etária entre 31 e 40 anos (grupo que avalia o mercado de trabalho como mais exigente), observa-se que as competências mais requeridas pelo mercado de trabalho foram o autocontrole emocional, que está relacionada à capacidade de administrar sentimentos e desenvolver habilidades pessoais para atingir metas anteriormente estipuladas (SIQUEIRA; BARBOSA; ALVES, 1999) e a capacidade empreendedora, que consiste em um processo complexo que envolve diversidade, incerteza (BARINI FILHO; CARDOSO, 2003) e a capacidade de definir o objetivo que determinará o seu próprio futuro (FILION, 2000). Em parte, uma possível explicação para que essas duas competências sejam vistas como mais requeridas pelos respondentes desta faixa etária, é a perspectiva de Schein (1978) que defende que a carreira sofre influência de três dimensões, quais sejam, o ciclo de vida biossocial, o ciclo de vida familiar e o ciclo profissional. Provavelmente esses respondentes, encontram-se na fase da crise dos 30 anos, iniciando uma vida conjugal e em processo de consolidação de carreira, o que sob o ponto de vista deles, demandam autocontrole emocional e capacidade empreendedora.

Sob o ponto de vista dos respondentes, em termos da contribuição da educação formal (GOHN, 2006) em nível 
superior no desenvolvimento de competências individuais requeridas pelo mercado de trabalho, as competências com maiores percentuais foram: comprometer-se com os objetivos da organização, capacidade de trabalhar em equipes, visão de mundo ampla e global e iniciativa de ação e decisão. Já no caso da contribuição da educação informal e não formal (GOHN, 2006) os maiores percentuais estão relacionados às competências: capacidade de trabalhar em equipes, capacidade de relacionamento interpessoal e capacidade de comprometer-se com os objetivos da organização. Considerando que há divergências e convergências na contribuição da modalidade educacional (GOHN, 2006) na formação de competências individuais, pode-se inferir, de um lado que, o tipo de modalidade educacional parece privilegiar a formação de um tipo específico de competência; e de outro, pela complementariedade e interdependência entre a educação formal, informal e não formal na formação de competências.

Esses resultados são convergentes com a perspectiva de Mintzberg (2006) por defender que a efetividade na formação de executivos somente será alcançada quando o treinamento prático ocupar posição importante ao lado do conhecimento cognitivo. De forma geral, esses aspectos indicam que a perspectiva de competência individual de Le Boterf (2003) está alinhada com as três modalidades educacionais apontadas por Gohn (2006) por articular os três eixos formados, pela pessoa em termos de sua biografia e socialização, pela sua formação educacional e pela sua experiência profissional; e é coerente com a compreensão de que o conceito de competência é mais efetivo quando tomado de forma conjunta os três níveis de compreensão apontados por Fleury e Fleury (2001) que abrangem simultaneamente os níveis da pessoa (competência individual), da organização (core competences) e dos países (sistemas educacionais e formação de competências).

Mesmo considerando a complementariedade e interdependência entre as três modalidades educacionais (GOHN, 2006), os resultados indicam, sob a ótica dos respondentes, que a contribuição da experiência de vida (educação informal e não formal) é maior do que a contribuição da formação de nível superior (educação formal) na formação de competências individuais. Essas constatações indicam a necessidade de reflexões tanto para o meio acadêmico quanto para o meio empresarial. 
Para o meio acadêmico torna-se relevante refletir sobre a formação educacional do administrador ofertada nos cursos de graduação. $O$ ensino de administração no Brasil, fortemente influenciado por orientações anglosaxônicas, sobretudo na reprodução de modelos importados dos Estados Unidos da América (ALCADIPANI; CALDAS, 2012) possui conotação funcionalista, que na visão de Boava; Boava e Sette (2014) concentramse mais na oferta de disciplinas instrumentais como marketing e gestão de pessoas e limitam o acesso do discente à disciplinas reflexivas como filosofia e criatividade entre outras. Esse aspecto associado ao fato de a prática docente ser predominantemente voltada para a transmissão de conhecimentos produzidos por terceiros (geralmente norteamericanos) pouco contribuem para o desenvolvimento de competências e habilidades do administrador por parte de muitas escolas de administração. Nesse sentido, a exemplo do que constaram Zago; Souza e Bezerra (2007) torna-se relevante repensar os cursos de graduação em administração de rever os métodos e os conteúdos curriculares de ensino e aprendizagem. Esse é um desafio complexo e que envolve, entre outros fatores, políticas públicas para a educação superior.
Para o meio empresarial essas reflexões voltam-se para os processos de recrutamento e seleção de pessoal. Tradicionalmente, esses processos que priorizam como critério a análise da educação formal em detrimento da educação informal e não formal, carecem de revisão rumo a uma análise mais holística e que priorizem como critério a análise de aspectos como socialização, história de vida, experiências entre outros.

Sintetizando, os resultados indicaram que na visão dos respondentes todas as quinze competências individuais investigadas são demandadas pelo mercado de trabalho, uma vez que os percentuais das escalas foram elevados. Esse nível de exigência elevado é observado quando novas formas de produção e maneiras de organizar o trabalho começam a surgir com a reestruturação do capitalismo, a partir do esgotamento do modelo taylorista/fordista. Dessa forma, um novo perfil de trabalhador passa a ser exigido para atender as novas demandas do mercado de trabalho (ZARIFIAN, 2001). O "trabalhador boi", aquele que apenas executa suas funções de acordo com o prescrito, sem ter consciência do seu trabalho, não é mais requerido em um contexto de constantes mudanças. É necessário um trabalhador multifuncional, 
criativo, comunicativo e com altos níveis de produtividade (ARAÚJO, 2001).

Entretanto, como constatado por Sant'anna; Moraes e Kilimnik (2005) em seus estudos, a exigência quanto a um novo perfil de trabalhador não tem sido acompanhada por políticas e práticas organizacionais coerentes com as competências requeridas. As organizações ainda mantêm uma postura de modernização conservadora com traços de centralização e tradicionalismo. Essa realidade também pode justificar o predomínio de homens em cargos de direção, enquanto as mulheres ocupam em sua maioria cargos operacionais.

\section{CONCLUSÕES}

O objetivo do estudo foi investigar o ponto de vista dos administradores inscritos no CRA/ES sobre o tema competência, mais especificamente sobre o processo de formação de competências que são requeridas pelo mercado de trabalho. Para isso, desenvolveu-se um estudo descritivo quantitativo por meio de uma pesquisa survey (BABBIE, 2005).

A pesquisa alcançou os seus objetivos ao apontar como síntese dos resultados que todas as quinze competências investigadas no estudo foram consideradas relevantes, merecendo destaque as três competências mais importantes, quais sejam, capacidade de trabalhar em equipes, capacidade de comprometer-se com os objetivos da organização e capacidade de gerar resultados efetivos. Além disso, concluiu-se que tanto a educação formal quanto a experiência de vida foram importantes no desenvolvimento de competências, porém, a experiência de vida (educação informal e não formal) foi considerada como a mais importante neste processo.

Os resultados alcançados e apresentados na seção anterior permitem diversas reflexões acerca do processo de formação de competências individuais, destacando-se: (a) a educação formal apontada por Gohn (2006) não é única no processo de formação de competências; (b) pelo contrário, a formação de competências ocorre ao longo da vida, articulando os três eixos defendidos por Le Boterf (2003) e as três modalidades de educação apontadas por Gohn (2006); (c) tipos específicos de competências parecerem privilegiar um tipo específico de modalidade educacional; (d) a educação informal e a não formal vinculadas à experiência da vida foram apontadas como mais relevantes na formação de competências do que a educação formal; (e) a compreensão do conceito de competência é 
mais efetiva quando são articulados de forma conjunta os três níveis de compreensão apontados por Fleury e Fleury (2001); e (f) a necessidade de repensar o processo de ensino e aprendizagem nos cursos de administração, sobretudo no sentido privilegiar uma formação mais reflexiva e holística.

Aponta-se como limitação do estudo a extensão geográfica do público-alvo que ficou restrita aos administradores registrados no CRA do Espírito Santo. Em razão disso, sugere-se a ampliação da pesquisa para alcançar outros conselhos regionais para, com isso, ampliar o grau de abrangência para outros contextos regionais e/ou nacional. Ainda como sugestão, seria relevante desenvolver pesquisas que relacionem a noção de competência individual (LE BOTERF, 2003), modalidades de educação (GOHN, 2006) e empregabilidade gerencial (HELAL; NEVES; FERNANDES, 2007). Mais especificamente, em relação às modalidades de educação, sugere-se o aprofundamento do tema por meio de abordagem qualitativa com vistas, por exemplo, a investigação de aspectos relacionados ao processo de ensino e aprendizagem, bem como à formação comportamental dos discentes nos âmbitos da educação formal, informal e não formal.
Espera-se que os resultados desta pesquisa e as sugestões de novos estudos possam contribuir para que pesquisadores, gestores organizacionais e responsáveis por políticas públicas reflitam sobre o processo de formação de competências nos níveis individual, organizacional e dos países (FLEURY; FLEURY, 2001). Nesse sentido, as reflexões trazidas no texto poderão auxiliar tanto a academia quanto o meio empresarial e o poder público na compreensão desse complexo fenômeno social que tem impacto no meio social, político e econômico de uma nação.

\section{REFERÊNCIAS}

ALCADIPANI, R.; CALDAS, M. P. Americanizing Brazilian management. Critical Perspectives on International Business, [S.1.], v. 8, n. 1, pp. 37-55, 2012.

ANTONELLO, C. S.; RUAS, R. Formação gerencial: pós-graduação lato sensu e o papel das comunidades de prática. RAC - Revista de Administração Contemporânea, Curitiba, v.9, n. 2, pp. 35-58, 2005.

ARAÚJO, R. M. L. Desenvolvimento de competências profissionais: as incoerências de um discurso. 2001.192 p. Tese (Doutorado em Educação), Faculdade de Educação da Universidade Federal de Minas Gerais, Belo Horizonte, 2001.

BABBIE, E. Métodos de pesquisas de survey. Belo Horizonte: Editora UFMG, 2005. 
BARINI FILHO, U.; CARDOSO, O. de O. A abordagem cognitiva na formação da competência empreendedora: o caso da Odebrecht. Administração em Diálogo, São Paulo, n. 5, pp. 65-76, 2003.

BOAVA, D. L. T.; BOAVA, F. M. F. M; SETTE, R. de S. Meditações funcionalistas: cinco reflexões sobre a administração.

Revista Administração em Diálogo, São Paulo, v. 16, n. 1, pp. 82-104, 2014.

BORBA, G.; FAGGION, G; SILVEIRA, T. Praticando o que ensinamos: inovação na oferta do curso de graduação em administração - gestão para inovação e liderança da UNISINOS. Revista Organizações \& Sociedade, Salvador, v. 12, n. 35, pp. 165-181, 2005.

BRASIL. Resolução Conselho Nacional de Educação / Câmara de Educação Superior $n^{\circ}$ 4, de 13 de julho de 2005. Institui as Diretrizes Curriculares Nacionais do Curso de Graduação em Administração. Diário Oficial [da] União, Brasília, 19 de julho de 2005, Seção 1, p. 26.

BOYATZIS, R.E. The Competent manager: a model for effective performance. New York: Wiley, 1982.

CARLI, L.; EAGLY, A. Gender, hierarchy and leadership: an introduction. Journal of Social Issues, [S.1.], v. 57, n. 4, pp. 629-636, 2001.

\section{DIEESE. Anuário das Mulheres}

Brasileiras 2011. São Paulo: DIEESE, 2011.

DUTRA, J. Gestão de pessoas com base em competências. In: DUTRA, J (Org.). Gestão por competência: um modelo avançado para o gerenciamento de pessoas. 3. ed. São Paulo: Editora Gente, 2001. pp. 25-43.
FILION, L. J. O empreendedorismo como tema de estudos superiores. In: INSTITUTO EUVALDO LODI (Org.).

Empreendedorismo, ciência, técnica e arte. Brasília: CNI - Instituto Euvaldo Lodi, 2000. pp. 13-42.

FLEURY, M. T. L; FLEURY, A. Construindo o conceito de competência. RAC - Revista de Administração Contemporânea, Curitiba, v.5, Edição Especial Art. 9, pp. 183-196, 2001.

GODOY, A. S.; ANTONELLO, C. S. Competências individuais adquiridas durante os anos de graduação de alunos do curso de administração de empresas. Revista Ciências da Administração, Florianópolis, v. 1, n. 23, pp. 157-191, 2009.

GOHN, M. da G. Educação não-formal, participação da sociedade civil e estruturas colegiadas nas escolas. Ensaio: aval. pol. públ. Educ., Rio de Janeiro, v.14, n.50, pp. 27-38, 2006

HELAL, D. H.; NEVES, J. A.; FERNANDES, D. C. Empregabilidade gerencial no Brasil. RAC-Eletrônica, Curitiba, v. 1, n. 2, art. 1, pp. 1-19, 2007.

INEP. Instituto Nacional de Estudos e Pesquisas Educacionais Anísio Teixeira. Censo da educação superior 2010: divulgação dos principais resultados do censo da educação superior 2010. Brasília: INEP, 2011.

KILIMNIK, Z. M.; SANT'ANNA, A. S; LUZ, T. R. da. Competências profissionais e modernidade organizacional: coerência ou contradição? RAE - Revista de Administração de Empresas, São Paulo, v. 44, Edição Especial Minas Gerais, pp. 10-21, 2004. 
LACRUZ, A. J.; VILLELA, L. E. Identidade do administrador profissional e a visão pósindustrial de competência: uma análise baseada na pesquisa nacional sobre o perfil do administrador coordenada pelo Conselho Federal de Administração. RAC-Eletrônica, Curitiba, v. 1, n. 2, Art. 3, pp. 34-50, 2007.

LE BORTEF, G. De la compétence: essai sur un attracteur étrange. Paris: Editions d'Organizations, 1994.

LE BOTERF, G. Desenvolvendo a competência dos profissionais. Porto Alegre: Artmed Editora, 2003.

LOUREIRO, P.; CARDOSO, C. C. O género e os estereótipos na gestão. Revista de Estudos Politécnicos, [S.1.], v. VI, n. 10, pp. 221-238, 2008.

\section{LUCHESA, C. J.; CHAVES NETO, A.}

\section{Cálculo do tamanho da amostra em} pesquisas em administração. Curitiba: Unicuritiba, 2011.

MCCLELLAND, D. C. Testing for competence rather than intelligence. American Psychologist, [S.1.], v, 28, n. 1, pp. 1-14, 1973.

\section{MESQUITA, J. M. C. Estatística} multivariada aplicada à administração: guia prático para utilização do SPSS. 1. ed. Curitiba: CRV, 2010.

MINTZBERG, H. Trabalho do executivo: o folclore e o fato. São Paulo: Nova Cultural. 1986. (Coleção Harvard de Administração, v. 3).

MINTZBERG, H. MBA? Não, obrigado: uma visão crítica sobre a gestão e o desenvolvimento de gerentes. Porto Alegre: Bookman, 2006.
MURARI, J; HELAL, D. H. O estágio e o desenvolvimento de competências profissionais em estudantes de Administração. Revista Gestão e Planejamento, Salvador, v. 10, n. 2, pp. 262-280, 2009.

NICOLINI, A. M. Fatores condicionantes do desenvolvimento do ensino de administração no Brasil. Revista Nacional ANGRAD, Rio de Janeiro, v.4, n1, pp.3-17, 2003.

NOGUEIRA; A. J. F. M.; BASTOS, F. C. Formação em administração: o gap de competências entre alunos e professores. REGE - Revista de Gestão, São Paulo, v. 19, n. 2, pp. 221-238, 2012

OLIVEIRA, Z. L. C. de. Trabalho e gênero: a construção da diferença. Mulher e Trabalho, [S.1.], v. 3, pp. 111-117, 2003.

PALHARES, J. A. Reflexões sobre o nãoescolar na escola e para além dela. Revista Portuguesa de Educação, [S.1.], v. 22, n. 2, pp. 53-84, 2009.

RUAS, R. L; FERNANDES, B. H. R; FERRAN, J. E. M; SILVA, F. M. da. Gestão por competências: revisão de trabalhos acadêmicos no Brasil no período 2000 a 2008. In: ENCONTRO NACIONAL DOS PROGRAMAS DE PÓS GRADUAÇÃO EM ADMINISTRAÇÃO, 34, 2010, Rio de Janeiro. Anais... Rio de Janeiro, ENANPAD, 2010.

RUAS, R; GHEDINE, T; DUTRA, J; BECKER, G; DIAS, G. O Conceito de competências de a à $\mathrm{z}$ : análise e revisão nas principais publicações nacionais entre 2000 e 2004. In: ENCONTRO NACIONAL DOS PROGRAMAS DE PÓS-GRADUAÇÃO EM ADMINISTRAÇÃO, 29, 2005, Brasília. Anais... Rio de Janeiro, ENANPAD, 2005. 
SANT'ANNA, A. S; MORAES, L. F. R; KILIMNIK, Z. M. Competências individuais, modernidade organizacional e satisfação no trabalho: um estudo de diagnóstico comparativo. RAE-Eletrônica, São Paulo, v. 4, n. 1, Art. 1, 2005.

SANT'ANNA, A. S. O movimento em torno da competência sob uma perspectiva crítica. In: HELAL, D. H; GARCIA, F. C; HONÓRIO, L. C. Gestão de pessoas e competência: teoria e pesquisa. Curitiba: Juruá, 2008. pp. 239-254.

SCHEIN, E. H. Career dynamics: matching individual and organizational needs. Massachussetts: Addison-Wesley, 1978.

SPENCER, L. M; SPENCER, S.

Competence at work. New York: John Wiley, 1993.

SIQUEIRA, M. M. M.; BARBOSA, N. C.; ALVES, M. T. Construção e validação fatorial de uma medida de inteligência emocional. Psicologia: Teoria e Pesquisa, [S.1.], v. 15, n. 2, pp. 143-152, 1999.

ZAGO, C. C.; SOUZA, C. C. B. de; BEZERRA, L. A. M. L. Competências profissionais do administrador: uma análise comparativa entre a necessidade do mercado e a formação dos administradores da Paraíba. Gestão.Org - Revista Eletrônica de Gestão Organizacional, Recife, v. 5, n. 2, pp. 210-225, 2007.

ZARIFIAN, P. O modelo da competência: trajetória histórica, desafios atuais e propostas. São Paulo: SENAC, 2003.

ZARIFIAN, P. Objetivo competência: por uma nova lógica. São Paulo: Atlas, 2001. 